\title{
Internal Structures of the Developing Brain Assessed by HDlive Imaging
}

\author{
Florin STAMATIAN', Dan BOITOR-BORZA ${ }^{1}$, Tunde KOVACS ${ }^{1}$ \\ Cluj-Napoca, Romania
}

\begin{abstract}
OBJECTIVES: The aim of this observational descriptive study of morphological research is to assess the nervous structures within the embryonic and early fetal brains not previously documented in litera-

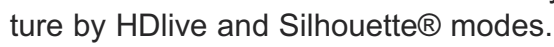

STUDY DESIGN: A total of 26 subjects were examined in vivo, i.e. 15 embryos and 11 fetuses in the first trimester of pregnancy ( 7 to 13 gestational weeks (GW)), using a transvaginal ultrasound using a Voluson E10, BT 15 scanner (GE Healthcare, Zipf, Austria).

RESULTS: The clear visualization of the brain structures by HDlive rendering mode was possible in all 26 selected optimal volumes. The most representative images for each week of gestation are shown. At $7 \mathrm{GW}$ the ultrasound semiology of the brain is simple. The choroid plexuses can be seen in the $4^{\text {th }}$ ventricle at $8 \mathrm{GW}$ and in the lateral ventricles at $9 \mathrm{GW}$ by HDlive mode. At $9 \mathrm{GW}$ the brain is developed enough so that the walls of the cerebral hemispheres, the ventricular system and the rhombic lips could be visualized by HDlive mode. At $10 \mathrm{GW}$ we depicted the ganglionic eminences within the brain by HDlive mode. At $11 \mathrm{GW}$ the thalamus was noticed. At $12 \mathrm{GW}$ and $13 \mathrm{GW}$, HDlive images of choroid plexus asymmetry and choroid plexuses cysts are shown.
\end{abstract}

CONCLUSIONS: The HDlive combined with Silhouette ${ }^{\circledR}$ mode can provide almost natural images of the internal structures of the embryonic and early fetal brain. Small-sized nervous structures such as the ganglionic eminences can be visualized using these facilities.

Keywords: HDlive, Silhouette mode, Developing brain, Ganglionic eminences

Gynecol Obstet Reprod Med 2016;22(2):66-71 DOI: 10.21613/GORM.2016.204

\section{Introduction}

3D sonography developed rapidly in the past two decades. It has been 25 years since Baba constructed the first 3D US system (1). In this period, the technology has constantly improved and finally the 3D US has become more contributive to the imaging diagnosis than the 2D US (2).

A special attention was given in obstetrics to the US assessment of the embryonic and fetal brains (3-5). 3D sonography allows obtaining important data on the spatial structure of the developing brain (4-7). Merging 3D US with transvaginal high-frequency sonography is a valuable method for morphological studies of the central nervous system (8). The most accurate images of the embryonic brain were obtained

\section{${ }^{I}$ IMOGEN Institute of Research Cluj-Napoca Department of Obstetrics and Gynecology University of Medicine and Pharmacy Cluj-Napoca, Romania}

Address of Correspondence: Dan Boitor-Borza

Clinica Obstetrică-Ginecologie 1, Str.

Clinicilor nr. 3-5, 400006 Cluj-Napoca,

Romania

dan.boitor@umfcluj.ro

Submitted for Publication:

05. 05. 2016

Accepted for Publication:

23. 05.2016 using miniaturized transcervical transducers, but they can only be employed in cases of subsequent termination of pregnancy $(9,10)$.

Modern US techniques and digital technology enable 3D virtual reconstruction of the developing brain. HDlive (highdefinition live) uses a virtual light source, which offers the possibility to create light and shadows effects, enhancing the depth perception (11). Creating virtual "shadows" allows obtaining almost photographical images which are very alike to the natural aspect of anatomical structures (12). By using these new facilities, understanding the brain development becomes easier and accessible to everyone. The modern US techniques serve also in improving the imaging diagnosis of congenital anomalies, some of which being subtle, but important (13).

The aim of this observational descriptive study of morphological research is to assess the nervous structures within the embryonic and early fetal brains not previously documented in literature by HDlive and Silhouette ${ }^{\circledR}$ modes.

\section{Material and Method}

Human embryos and fetuses

From March 2015 to May 2015, a total of 26 subjects, i.e. 15 embryos and 11 fetuses corresponding to each week be- 
tween 7 and $13 \mathrm{GW}$ were studied in vivo. The gestational age was calculated by the crown-rump length (CRL) of the subjects and was expressed as completed weeks from the last menstrual period (gestational weeks, GW).

The including criteria were: singleton pregnancies; absence of gross anomalies of the cephalic extremity and of the rest of the body.

The study protocol was approved by the local ethics committee. Written informed consent was obtained from each patient before the procedure, according to the World Medical Association Declaration of Helsinki, revised in 2000, Edinburgh.

\section{Acquisition of images}

The embryos and fetuses were assesed in vivo by transvaginal US using a Voluson E10, BT 15 scanner (GE Healthcare, Zipf, Austria). We used a mechanical high-frequency transducer (6-12 MHz/ 256-element 3D/4D). With this technique the volume acquisition took only a few seconds at an angle of $70^{\circ}-85^{\circ}$. The HDlive rendering mode was performed routinely as the subjects were scanned.

\section{Image post-processing}

All volume data were reviewed retrospectively and 26 optimal volumes, one for each subject, were selected for further analysis. The criteria of inclusion were: absence of movement artifacts and accurate visualization of the internal structures of the brain.

The optimal volumes were examined using the 3D HDlive rendering mode. The Silhouette ${ }^{\circledR}$ mode was employed for underlying the walls of the cerebral cavities.

The nervous structures within the brain were identified according to their anatomical features described in the classical atlases of embryology and histology (14-17).

\section{Results}

The characteristics of the subjects are presented in table 1 .

The clear visualization of the brain structures by HDlive rendering mode was possible in all 26 selected optimal volumes. The most representative images for each week of gestation are shown (Figure 1-8).
At $7 \mathrm{GW}$ the ultrasound semiology of the brain is simple, since only the hypoechoic cavities of the cerebral vesicles and the flexures of the neural tube are visible (Figure 1).

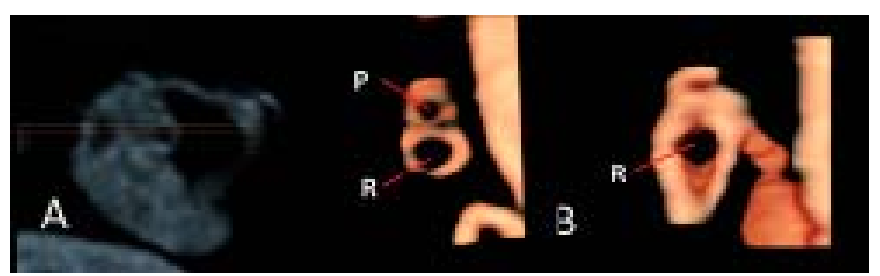

Figure 1: Human embryo $12 \mathrm{~mm}$ CRL, $7 \mathrm{GW}$ imaged by HDlive. Axial (A) and coronal (B) slices are shown. The characteristic shape of rhombencephalon is well depicted. P: Prosencephalon, R: Rhombencephalon

At $8 \mathrm{GW}$ the early lateral ventricles are seen as the falx cerebri begins to separate them (Figure 2).

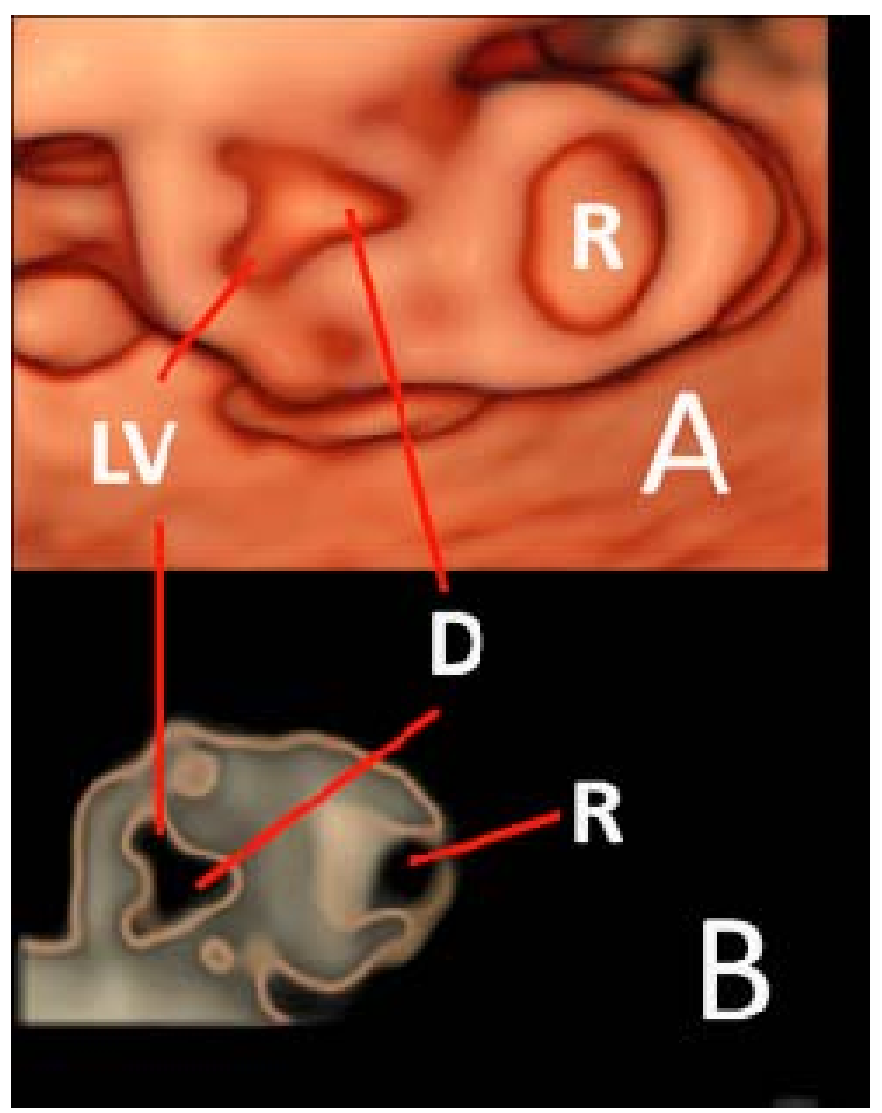

Figure 2: Human embryo $17 \mathrm{~mm} C R L, 8 \mathrm{GW}$ imaged by $3 D$ transvaginal US. HDlive (A) and Silhouette $(B)$ images in an axial section are presented. D:Diencephalon, $R$ : Rhombencephalon, LV: Early lateral ventricles

Table 1: Characteristics of the subjects

\begin{tabular}{|c|c|c|c|c|c|c|c|}
\hline GW & 7 & 8 & 9 & 10 & 11 & 12 & 13 \\
\hline $\mathrm{N}$ & $4(15.38 \%)$ & $4(15.38 \%)$ & $3(11.53 \%)$ & $4(15.38 \%)$ & $3(11.53 \%)$ & $3(11.53 \%)$ & $5(19.23 \%)$ \\
\hline $\mathrm{CRL}(\mathrm{mm})$ & $9-15$ & $17-22$ & $23-29$ & $31-38$ & $42-50$ & $55-64$ & $67-77$ \\
\hline \multicolumn{8}{|l|}{$\min -\max$} \\
\hline mean $\pm S D$ & $12 \pm 2.449$ & $19.50 \pm 2.082$ & $25.33 \pm 3.215$ & $35 \pm 2.944$ & $44.67 \pm 4.619$ & $59.67 \pm 4.509$ & $70.2 \pm 4.087$ \\
\hline $95 \% \mathrm{Cl}$ & $8.102-15.90$ & $16.19-22.81$ & 17.35-33.32 & $30.32-39.68$ & $33.19-56.14$ & $48.47-70.87$ & $65.13-75.27$ \\
\hline
\end{tabular}

GW: Gestational weeks, CRL: Crown-rump length 
The choroid plexuses can be seen in the $4^{\text {th }}$ ventricle at 8 GW (Figure 3) and in the lateral ventricles at $9 \mathrm{GW}$ (Figure 4) by HDlive mode.

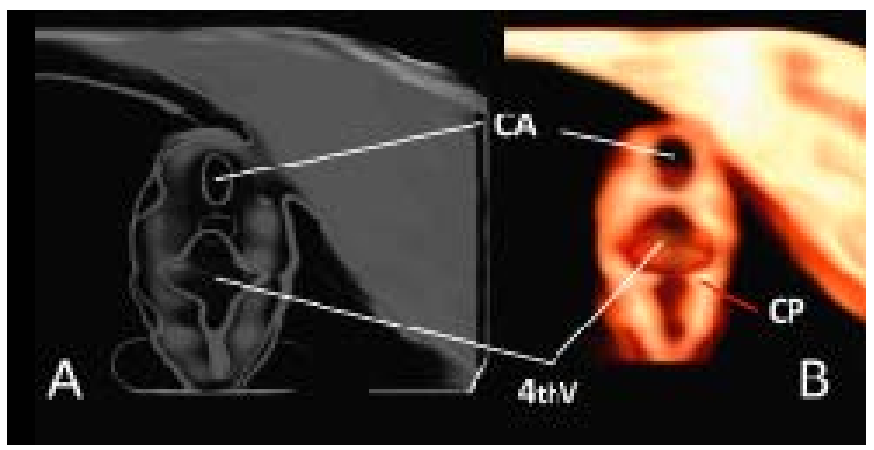

Figure 3: Human embryo $17 \mathrm{~mm} C R L, 8 \mathrm{GW}$ imaged by Silhouette (A) and HDlive (B) modes. CA: Cerebral aqueduct, $4^{\text {th }} \mathrm{V}$ : Fourth ventricle, $C P$ : Choroid plexus

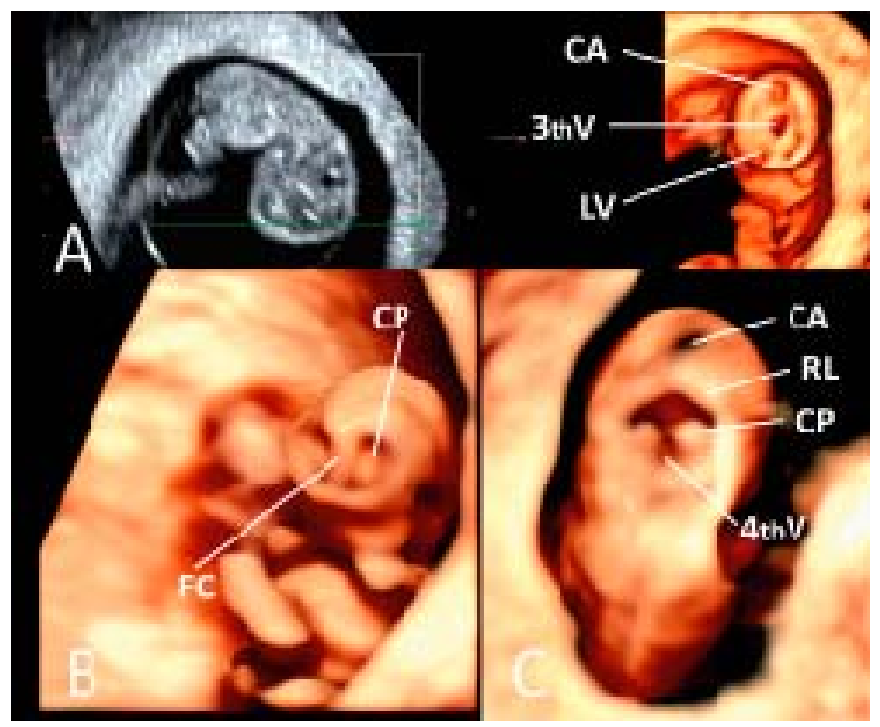

Figure 4: Human embryo $23 \mathrm{~mm}$ CRL, 9 GW imaged by HDlive mode. Axial $(A)$, anterior $(B)$ and posterior $(C)$ views are shown. CA: cerebral aqueduct, $3^{\text {th }} \mathrm{V}$ : Third ventricle, LV: Lateral ventricles, FC: Falx cerebri, CP: Choroid plexus, RL: Rhombic lips, $4^{\text {th }} \mathrm{V}$ : Fourth ventricle

At $9 \mathrm{GW}$ the brain is developed enough so that the walls of the cerebral hemispheres, the ventricular system and the rhombic lips could be visualized by HDlive mode (Figure 4).

At $10 \mathrm{GW}$ we depicted the ganglionic eminences within the brain by HDlive mode (Figure 5).

At $11 \mathrm{GW}$ the thalamus was noticed (Figure 6). The isthmul rhombencephali, i.e. the communication between the cerebral aqueduct within the mesencephalon and the fourth ventricle, is visible in figure 6 panel (C).

At $12 \mathrm{GW}$ and $13 \mathrm{GW}$ the internal structures of the developing brain can be clearly depicted (Figure 7).

An anatomical variation (choroid plexus asymmetry) is presented in figure 9. Images of choroid plexuses cysts are shown in figure 10 .

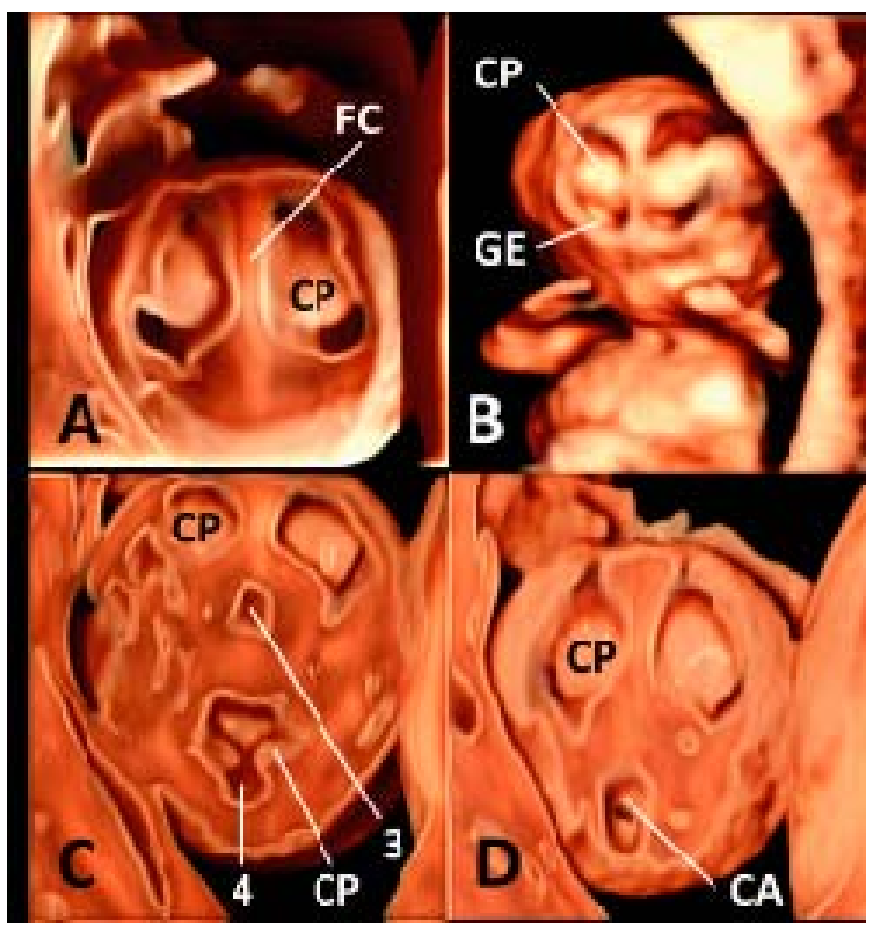

Figure 5: Human embryo $31 \mathrm{~mm}$ CRL, $10 \mathrm{GW}$ imaged by HDlive combined with Silhouette mode. Coronal $(A, B)$ and axial $(C, D)$ slices are presented. FC: Falx cerebri, CP: Choroid plexus, GE: Ganglionic eminence, 3: Third ventricle, 4: Fourth ventricle, CA: Cerebral aqueduct

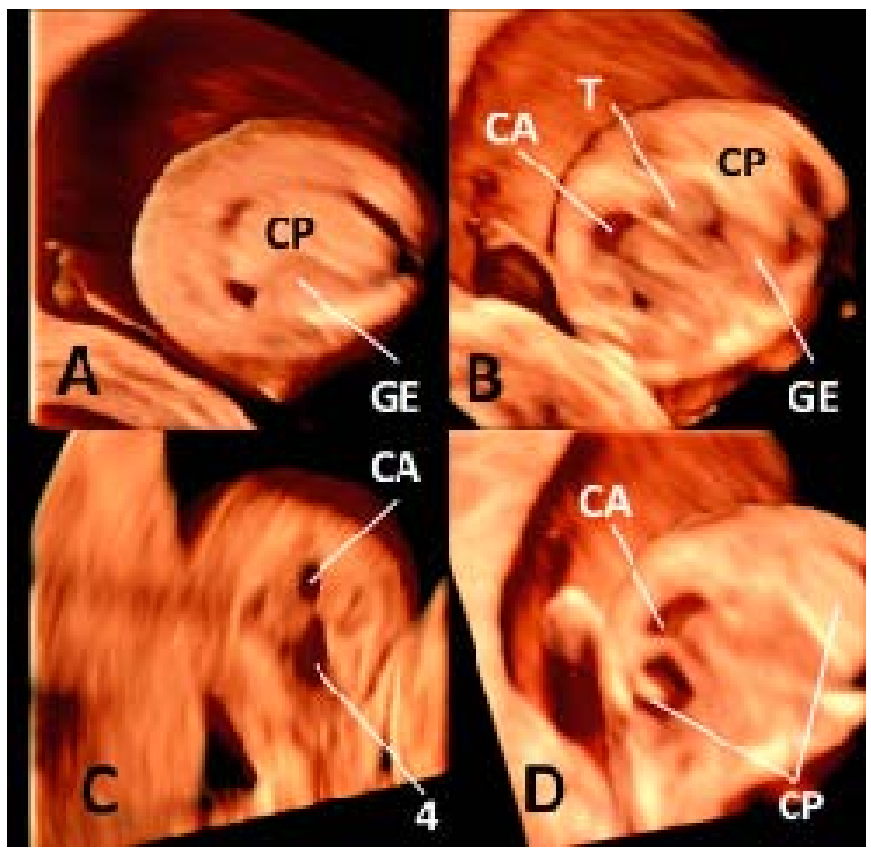

Figure 6: Human embryo $44 \mathrm{~mm} C R L, 11 \mathrm{GW}$ imaged by HDlive mode. Right lateral views $(A, B)$, coronal $(C)$ and sagittal (D) sections through the posterior fossa are shown. CP: Choroid plexus, GE: Ganglionic eminence, T: Thalamus, CA: Cerebral aqueduct, 4: Fourth ventricle 


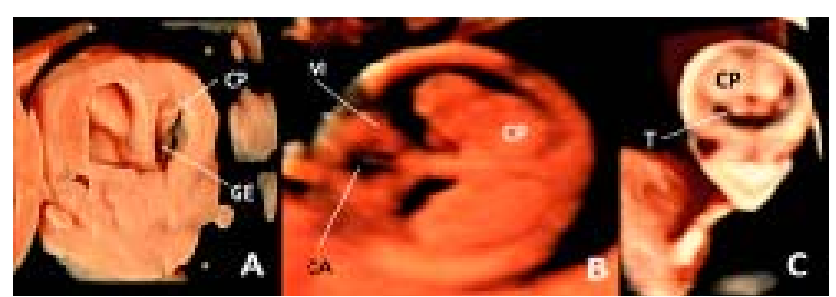

Figure 7: Human embryo $55 \mathrm{~mm} C R L, 12 \mathrm{GW}$ imaged by HD live mode. "Any plane" sections $(A, B)$ are shown. T: Thalamus, $4^{\text {th }}$ V: Fourth ventricle, CP: Choroid plexus, GE: Ganglionic eminence

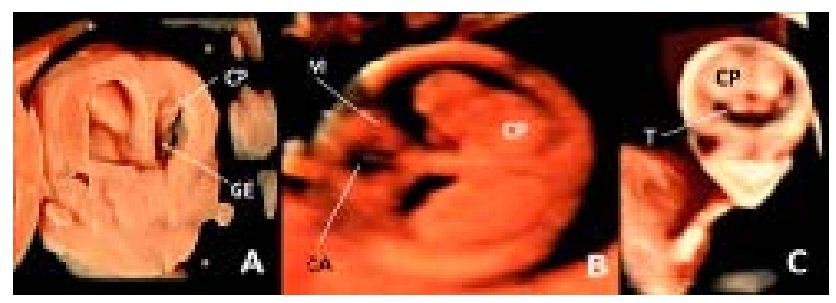

Figure 8: Human embryo $68 \mathrm{~mm} C R L, 13 \mathrm{GW}$ imaged by HDlive mode combined with Silhouette ( $A$, coronal view) and HDlive only ( $B$, axial view). $C P$ : Choroid plexus within the lateral ventricles, GE: Ganglionic eminence, M: Mesencephalon, CA: Cerebral aqueduct, T: Thalamus

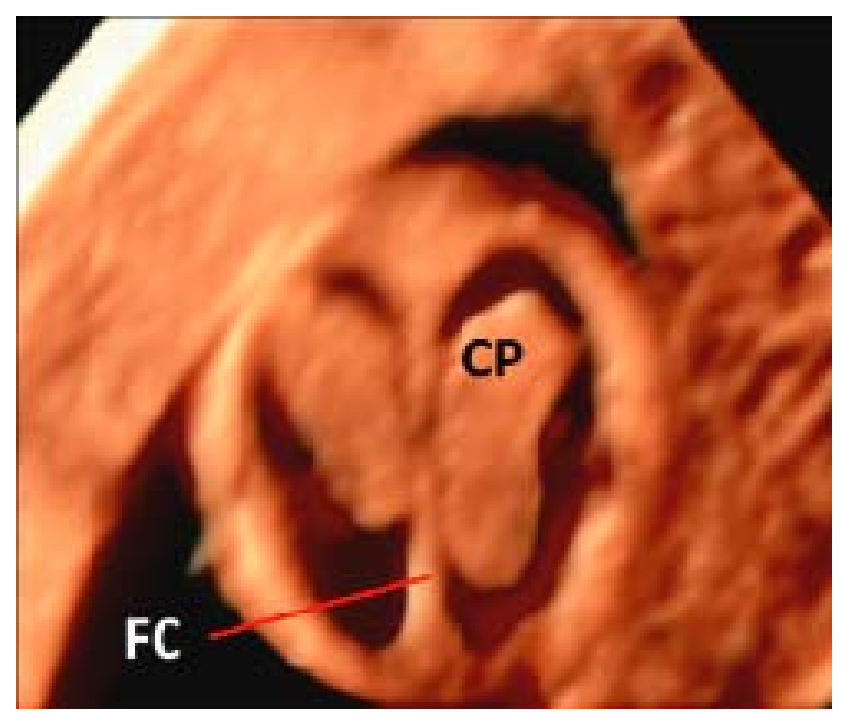

Figure 9: Human embryo $59 \mathrm{~mm}$ CRL, $12 \mathrm{GW}$. Choroid plexus asymmetry. HDlive image, axial section. FC: Falx cerebri, CP: Choroid plexuses within the lateral ventricles

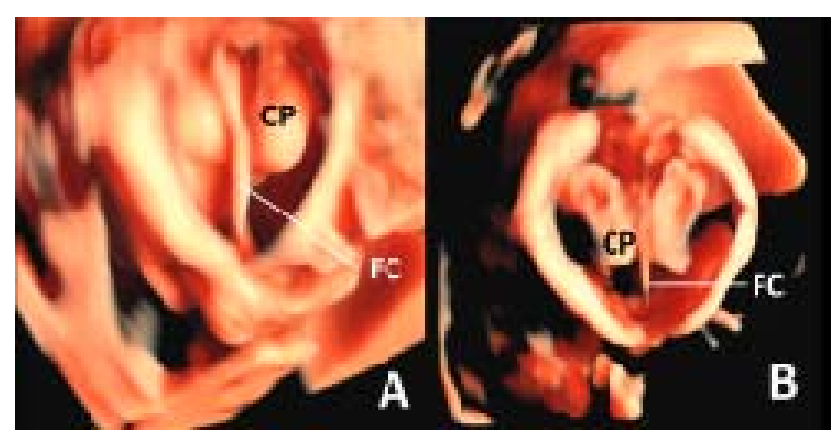

Figure 10: Human embryo $75 \mathrm{~mm}$ CRL, $13 \mathrm{GW}$ imaged by HDlive. Axial sections $(A, B)$. Bilateral choroid plexus cysts. Even if the lateral ventricles seem to be enlarged the diagnostic of "ventriculomegaly" is not sure at this gestational age. FC: Falx cerebri, CP: Choroid plexuses within the lateral ventricles

\section{Discussion}

US is the main method employed for in vivo assessment of the developing brain. It has some undeniable advantages, as it is non-invasive, inoffensive and affordable. It provides a realtime visualization of the brain (18). Unfortunately, this method is limited by the poor spatial resolution and low tissue contrast, which causes some nervous structures to be indistinct (19-21).

The HDlive mode provides almost natural images of some brain structures (6), especially of those surrounded by cerebrospinal fluid, such as the choroid plexuses or ganglionic eminences (GE). Furthermore, the rendered images can be more easily understood than those provided by conventional 3D US $(7,12,22)$. The HDlive images are very impressive both for doctors and parents, thus the communication between them being improved, especially in the case of congenital anomalies $(13,23)$.

We found articles in literature reporting the utility of the HDlive mode for visualizing the whole embryonic or fetal body, the heart, placenta and umbilical cord (13,23-26). No references concerning the visualization of the internal structures of the developing brain, such as the GE, were found.

It was stated that the HDlive mode provides realistic images of the surface anatomy of embryos and fetuses (13). We have shown that this US mode is able to provide almost photographic images of the internal structures of the developing brain as well.

A particular advantage of the HDlive mode is the possibility of processing all the volumes within the memory of the US machine (13), no special acquisition being required.

In our study we visualized by HDlive mode the choroid plexuses within the fourth ventricle in an embryo of $17 \mathrm{~mm}$ CRL $(8 \mathrm{GW})$ and those within the lateral ventricles in an embryo of $23 \mathrm{~mm}$ CRL ( $9 \mathrm{GW}$ ), respectively. This gap in the development of the choroid plexuses of the above-mentioned ventricles has been reported in previous studies (27). The choroid plexus of the third ventricle develops later in the early fetal period.

The anatomy of the studied embryos is labeled as "normal", given the similarity to the features described in other studies $(3,28-30)$. Defining the "normal anatomy" of the embryo is needed in order to identify the congenital anomalies in an early stage of development (31). For-instance, the size of the cerebral ventricles is very variable during the first trimester (27). For this reason, terms like "hydrocephaly" and "ventriculomegaly" should be avoided in this period.

A good knowledge of the US morphology of the developing brain is useful to both US specialists and clinicians, since congenital anomalies tend to be detected as early as possible 
in pregnancy (32). Therefore, the diagnosis of brain anomalies by US in the first trimester of pregnancy is a challenge (34). The HDlive mode may improve the accuracy of the congenital anomalies diagnosis due to the high-quality of the rendered images (34-37).

At the end of the embryonic period the morphology of the brain is more complex. At $10 \mathrm{GW}$ the thalamus, GE and the walls of the mesencephalon can be clearly depicted. We demonstrated by transvaginal high-frequency US the GE in an embryo of $31 \mathrm{~mm} \mathrm{CRL}(10 \mathrm{GW})$, both in the 3D volumes using the OmniView ${ }^{\circledR}$ software and by HDlive mode (38). We failed to precisely visualize the GE at $9 \mathrm{GW}$ because those structures are very small at this age. In the studied literature no reference concerning the US visualization of the GE in the first trimester of pregnancy was found.

The 3D high-frequency transvaginal US is a feasible method for visualizing the developing brain structures, as it provides acceptable quality images for clinical studies. We have demonstrated that using 3D transvaginal US and its modern facilities (HDlive mode, OmniView ${ }^{\circledR}$ software and Silhouette ${ }^{\circledR}$ mode), small-sized nervous structures can be almost photographically depicted (38).

The applicability and clinical importance of the new US technologies and softwares are to be confirmed by further studies. A limitation of our study is that we described a small population of embryos and fetuses. The challenge will probably be to evaluate the sensitivity and specificity, negative and positive predictive value of discovering unusual features of the early developing brain in the field of screening fetal abnormalities.

However, early fetal US (before 10 weeks) is not a standard of care in most countries. From an economic perspective it will be difficult to justify such US routine in order to screen for early abnormalities, but the prenatal diagnosis of fetal anomalies tend to be moved from the second to the first trimester of pregnancy (32). In our opinion these new facilities could play an important role in the improvement of the sensitivity of the US detection of congenital anomalies in the early pregnancy.

For moment, the interest of such morphological studies is only scientific. The advances in US techniques and the wide availability of the new technology facilitated the understanding of ontogeny in embryonic stages. The knowledge which once was available only to embryologists, as presented in a rather abstract form (schemes, drawings, photographs of histological preparations) is now easily understood by practitioners.

We conclude that a good knowledge of embryology is fundamental for understanding the onset of congenital anomalies and for a correct interpretation of the images provided by the modern techniques.

\section{References}

1. Baba K, Satoh K, Sakamoto S, Okai T, Ishii S. Development of an ultrasonic system for three-dimensional reconstruction of the fetus. J Perinat Med 1989;17: 19-24.

2. Tonni G, Martins WP, Filho HG, Araujo jr. E. Role of 3-D ultrasound in clinical obstetric practice:evolution over 20 years. Ultrasound Med Biol 2015;41(5):1180-1211.

3. Blaas HGK, Eik-Nes SH. Sonoembryology and early prenatal diagnosis of neural anomalies. Prenat Diagn 2009; 29:312-25.

4. Pretorius DH, Nelson TR. Three-dimensional ultrasound. Ultrasound Obstet Gynecol 1995;5:219-21.

5. Merz E. Three-dimensional ultrasound-a requirement for prenatal diagnosis. Ultrasound Obstet Gynecol 1998;12: 225-6.

6. Kurjak A, Kupesic S, Banovič I, Hafner T, Kos M. The study of morphology and circulation of early embryo by three-dimensional ultrasound and power Doppler. J Perinat Med 1999;27:145-57.

7. Pooh RK, Pooh K. Assessment of Fetal Central Nervous System. Donald School J Ultrasound Obstet Gynecol 2013;7(4):369-84.

8. Pooh RK. Contribution of Trans-Vaginal High-Resolution Ultrasound in Fetal Neurology. Donald School J Ultrasound Obstet Gynecol 2011;5(2):93-9.

9. Tanaka H, Senoh D, Yanagihara T, Hata T. Intrauterine sonographic measurement of embryonic brain vesicle. Hum Reprod 2000;15(6):1407-12.

10. Tanaka H, Hata T. Intrauterine sonographic measurement of the embryonic brain mantle. Ultrasound Obstet Gynecol 2009;34:47-51.

11. Timor-Tritsch IE, Peisner DB, Raju S. Sonoembryology: an organ-oriented approach using a high-frequency vaginal probe. J Clin Ultrasound 1990;18:286-98.

12. Bonilla-Musoles F, Raga F, Osborne NG, Bonilla F Jr, Caballero O, Climent MT, Wallraf SH, Castillo JC. Multimodality 3-Dimensional Volumetric Ultrasound in Obstetrics and Gynecology With an Emphasis in HDlive Technique. Ultrasound Q 2013;29(3):189-201.

13. Pooh RK, Kurjak A. Novel application of three-dimensional HDlive imaging in prenatal diagnosis from the first trimester. J Perinat Med 2015;43(2):147-58.

14. O'Rahilly R, Müller F. Significant features in the early prenatal development of the human brain. Ann Anat 2008; 190:105-118

15. Bayer SA, Altman J. The human brain during the early first trimester. Taylor \& Francis Group: Boca Raton, Florida, USA, 2006.

16. Bayer SA, Altman J. The human brain during the early first trimester. Taylor \& Francis Group: Boca Raton, 
Florida, USA, 2008.

17. O'Rahilly R, Müller F. The Embryonic Human Brain: An Atlas Of Developmental Stages. 3rd Edition. John Wiley \&Sons: Hohoken, New Jersey, USA, 2006.

18. Liu F, Zhang Z, Lin X, et al. Development of the human fetal cerebellum in the second trimester: a post mortem magnetic resonance imaging evaluation. J Anat 2011;219: 582-588.

19. Malinger G, Lev D, Lerman-Sagie T. The fetal cerebellum. Pitfalls in diagnosis and management. Prenat Diagn 2009;29:372-80.

20. Mighell AS, Johnstone ED, Levene M. Post-natal investigations: management and prognosis for fetuses with CNS anomalies identified in utero excluding neurosurgical problems. Prenat Diagn 2009;29:442-9.

21. Vazquez E, Mayolas N, Delgado I, Hiqueras T. Fetal neuroimaging: US and MRI. Pediatr Radiol 2009;39:422-35.

22. Hata T, Hanaoka U, Tenkumo C, Sato M, Tanaka H, Ishimura M. Three- and four-dimensional HDlive rendering images of normal and abnormal fetuses: pictorial essay. Arch Gynecol Obstet 2012;286(6):1431-5.

23. Hata T, Hanaoka U, Tenkumo C, Sato M, Tanaka H, Ishimura M. Three- and four-dimensional HDlive rendered images of normal and abnormal fetuses: pictorial essay. Arch Gynecol Obstet 2012; 286:1431-5.

24. Filho SMZ, Araujo Jr. E, Filho HAG, Pires CR, Nardozza LMM, Moron AF. Sonoembryology by three-dimensional ultrasonography: pictorial essay. Arch Gynecol Obstet 2007;276:197-200.

25. Merz E, Pashaj S. Current role of 3D/4D Sonography in Obstetrics and Gynecology. Donald School J Ultrasound Obstet Gynecol 2013;7(4):400-8.

26. Grisolia G, Tonni G. Fetal echocardiography using HDlive. J Obstet Gynaecol Can 2013;35(6):497-8.

27. O'Rahilly R, Müller F. Prenatal development of the brain. In Ultrasonography of the prenatal brain, Timor-Tritsch I, Monteagudo A, Pilu G, Malinger G (eds). $3^{\text {rd }}$ edition. The McGraw-Hill Companies: New York 2012;1-14.

28. Kim MS, Jeanty P, Turner C, Benoit B. Three-dimensional sonographic evaluations of embryonic brain development.
J Ultrasound Med 2008;27:119-124.

29. Pooh RK, Shiota K, Kurjak A. Imaging of the human embryo with magnetic resonance imaging microscopy and high-resolution transvaginal 3-dimensional sonography: human embryology in the $21^{\text {st }}$ century. Am J Obstet Gynecol 2011;204:77.

30. Hata T, Dai SY, Kanenishi K, Tanaka H. Three-dimensional volume-rendered imaging of embryonic brain vesicles using inversion mode. J Obstet Gynaecol Res 2009; $35: 258-61$.

31. Pooh RK. Neurosonoembryology by three-dimensional ultrasound. Semin Fetal Neonatal Med 2012;17:261-8.

32. Pooh RK, Kurjak A. 3D/4D sonography moved prenatal diagnosis of fetal anomalies from the second to the first trimester of pregnancy. J Matern Fetal Neonat Med 2012; 25(5):433-55.

33. Gijtenbeek M, Bogers H, Groenenberg IAL, Exalto N, Willemsen SP, Steegers EA, Eilers PH, SteegersTheunissen RP. First trimester size charts of embryonic brain structures. Hum Reprod 2014;29(2):201-7.

34. Shaw SW, Hsieh TT, Hsu JJ, Lee CL, Cheng PJ. Measurement of nuchal volume in the first trimester Down screening using three-dimensional ultrasound. Prenat Diagn 2009;29:69-73.

35. Bhaduri M, Fong K, Toi A, Tomlinson G, Okun N. Fetal anatomic survey using three-dimensional ultrasound in conjunction with first-trimester nuchal translucency screening. Prenat Diagn 2010;30:267-73.

36. Cho HY, Kwon JY, Kim YH, Lee KH, Kim J, Kim SY, Park YW. Comparison of nuchal translucency measurements obtained using Volume NT (TM) two- and three-dimensional ultrasound. Ultrasound Obstet Gynecol 2012; 39:175-180.

37. Chen PW, Chen M, Leung TY, Lau TK. Effect of image settings on nuchal translucency thickness measurement by a semi-automated system. Ultrasound Obstet Gynecol 2012;39:169-74.

38. Boitor-Borza D, Kovacs T, Stamatian F. Ganglionic eminence within the early developing brain visualized by 3D transvaginal ultrasound. Med Ultrason 2015;17(3): 289-94. 